\title{
Characteristic Relationships between Phosphorous Accrual, Ecosystem Aspects and Water Level Fluctuations in Tropical Lakes: Naivasha Ramsar Site, Kenya
}

\author{
Beatrice N. Obegi ${ }^{1,2}$, George M. Ogendi ${ }^{3,4}$, Reuben Omondi², Boston J. Siriba ${ }^{2}$, \\ George N. Morara ${ }^{1,2}$, Nehemiah M. Rindoria ${ }^{5}$, Paul Orina ${ }^{6}$ \\ ${ }^{1}$ Kenya Marine and Fisheries Research Institute, Naivasha, Kenya \\ ${ }^{2}$ Department of Aquatic and Fishery Sciences, Kisii University, Kisii, Kenya \\ ${ }^{3}$ Department of Environmental Science, Egerton University, Kenya \\ ${ }^{4}$ Dryland Research Training \& Ecotourism Centre, Chemeron, Egerton University, Kenya \\ ${ }^{5}$ Department of Biological Sciences, Kisii University, Kisii, Kenya \\ ${ }^{6}$ Kenya Marine and Fisheries Research Institute, Kegati, Kenya \\ Email: *obegibeatrice@gmail.com
}

How to cite this paper: Obegi, B. N., Ogendi, G. M., Omondi, R., Siriba, B. J., Morara, G. N., Rindoria, N. M., \& Orina, P. (2021). Characteristic Relationships between Phosphorous Accrual, Ecosystem Aspects and Water Level Fluctuations in Tropical Lakes: Naivasha Ramsar Site, Kenya. Journal of Geoscience and Environment Protection, 9, 53-67.

https://doi.org/10.4236/gep.2021.91004

Received: December 11, 2020

Accepted: January 19, 2021

Published: January 22, 2021

Copyright $\odot 2021$ by author(s) and Scientific Research Publishing Inc. This work is licensed under the Creative Commons Attribution International License (CC BY 4.0).

http://creativecommons.org/licenses/by/4.0/ (c) (i) Open Access

\begin{abstract}
Hydrological dynamics affect water levels and thus affecting ecosystem structure and functions. Lake levels in tropical ecosystems affect phosphorous input through runoff from adjacent watersheds. The resultant biological community, water and sediment quality of the lakes due to water level changes is a reflection of the geology of the area and the anthropogenic activities in the watershed. The study conducted between January 2018 and December 2019 was to explore relationships between the phosphorous input and Water Level Fluctuations (WLF) recorded by Water Resource Authority (WRA). Lake water samples were analyzed in the laboratory for phosphorous using molybdenum blue-ascorbic method and recorded using spectrophotometer. Chlorophyll- $a$ was determined by extracting a filtered sample with $15 \mathrm{ml}$ acetone and incubating overnight and thereafter read using a double beam spectrophotometer. Total Suspended Solids (TSS) was determined by filtering $200 \mathrm{ml}$ of a water sample and dried overnight at $105^{\circ} \mathrm{C}$. The lowest and highest phosphorous concentrations recorded were $0.2 \mathrm{mg} / \mathrm{l}$ and $0.42 \mathrm{mg} / \mathrm{l}$ at NST7 and NST2, respectively. Measurements of Chlorophyll- a were 0.32 $\mathrm{mg} / \mathrm{l}$ and $0.42 \mathrm{mg} / \mathrm{l}$ at NST9 and NST2, respectively. Secchi transparency measurements were $32.9 \mathrm{~cm}$ at NST3 and $84 \mathrm{~cm}$ at NST1. The highest and lowest TSS concentrations were $0.14 \mathrm{mg} / \mathrm{l}$ and $0.13 \mathrm{mg} / \mathrm{l}$ at NTS1 and NST8, respectively. The hydrodynamic regime in most tropical lakes plays a signifi-
\end{abstract}


cant role in the re-reaction of phosphorous that consequently influences productivity. Tropical lakes have extreme lake level fluctuations which accelerate the production process. The influence of water level changes on aquatic productivity is crucial in most tropical lakes and should be taken into consideration when assessing the environmental impacts.

\section{Keywords}

Lake Level Fluctuations, Total Phosphorous, Ecosystem Aspects, Lake Naivasha

\section{Introduction}

Lacustrine systems worldwide provide diverse functions for aquatic biota. Lake Naivasha as a ramsar site has experienced WLF over years. Lake level fluctuations are often driven by human activities and climate change which mostly affect Phosphorous loading. Increasing phosphorous accumulation in Lakes is an indication of increasing eutrophication (Stoof-Leichsenring et al., 2011). In most tropical lakes and reservoirs water levels and nutrient enrichment enhance their productivity and ecosystem functioning (Bot \& Colijn, 1996; Mavuti, Moreau, \& Munyandorero, 1996b). WLF is quite important in nutrient regeneration in the riparian land. The shallow area of a lake is believed to be the main sink of nutrients which are usually released during high water levels (Jones \& Lee, 1982; Gownaris et al., 2018). In addition, nutrient input may enter the lake through agricultural, municipal and industrial runoff (Gaudet \& Muthuri, 1981; Gaudet \& Melack, 1981). Phosphorous attached to substrates on the littoral zone is released into the water column during biogeochemical reactions (Gaudet, 2014; Gaudet, 1979; Gaudet, 1977; Melack, 1979). The lake also experiences dry seasons and as a result shallow areas are exposed, the bare soil is enriched by the animal dung as well as use of fertilizers by small scale farmers. A rise in water level results in the release of large amounts of nutrients from the submerged plants and covered wastes (Gaudet \& Muthuri, 1981; Howard-Williams \& Lenton, 1975; Mclachlan, 1971) and that promotes phytoplankton biomass.

Chlorophyll-a concentration across trophic gradient of lakes is normally used to predict phytoplankton biomass (Gikuma-Njuru \& Hecky, 2005). Nitrogen and phosphorous play a huge role in determining the maximum algal biomass reaching in a water body (Hecky \& Kling, 1981). When the load of phosphorous, which is a limiting nutrient for algal growth is decreased, a decrease in maximum algal biomass is likely to occur (Jones \& Lee, 1982).

This enrichment of phosphorous and presence of light predicts the algal growth in the lake, although in tropical lakes nitrogen depletion may occur and thus reduce algal productivity (Kalff, 1983; Richardson, 1985; Moed \& Hallegraeff, 1978; Mavuti et al., 1996b; Lee \& Jones, 1980). Tropical lakes accumulate higher concentrations of phosphorous than the temperate zones (Kitaka et al., 
2002). Various studies (Talling, 2001; Pacini et al., 2018; Kalff, 1983) have shown that Lake Naivasha usually has higher levels of phosphorous than nitrogen. A study undertaken on the trophic state of the River Malewa flowing into the lake (Kitaka, Harper, \& Mavuti, 2002) showed that the seasonal rainfall patterns are responsible for the changes in lake levels. Studies by Zwieten et al. (2011) noted that water level fluctuations of many freshwater ecosystems influence the ecology which in turn influences their productivity (Richardson \& Heilmann, 1995; Kolding \& Zwieten, 2012). According to Kilham (1990), when the water level increases, chemical interactions between ecotones occur. Littoral zone changes, occurring during the rainy and dry seasons, leading to the accumulation and dissolving of nutrients thus enhancing productivity (Talling, 1992; Kalff \& Brumelis, 1993; Junk et al., 1989). Several studies have shown that accumulation of total phosphorous in the lakes contributes to phytoplankton biomass and sustainability of other aquatic flora and fauna (Kalffi, 1986; Hickley et al., 2002).

Water transparency provides an important characteristic in many tropical lakes and is frequently used to determine the suitability of lake ecosystems (Chapman, 1996). The clarity of tropical lakes, specifically Lake Naivasha, is normally reduced by incoming sewage wastes, runoff from heavy rain which carries suspended materials, sediments and microscopic organisms which can be measured as (TSS). Increased turbidity leads to growth of submerged microphytes (Briton et al., 2007). A high rate of sediment accumulation from increased human activity in the catchment influences the status of water quality (Krienitz et al., 2013; Stoof-leichsenring, 2011). The effect of reduced water transparency on light penetration has been shown by (Roach \& Winemiller, 2014; Stoof-leichsenring et al., 2012).

Although most studies have investigated the effects of WLF in tropical lakes (Odongo et al. 2015; Kolding et al., 2016), there are some knowledge gaps on the relationships of such fluctuations with phosphorous input, as well as on the water clarity and Chlorophyll-a concentration in enhancing productivity. Lake Naivasha being a shallow ephemeral lake, fluctuations are driven by rainfall patterns, consequently making it dynamic both in its ecology and species diversity (Pacini et al., 2018). Other studies (Hubble \& Harper, 2002; Harper, 1990; Becht et al., 2002) have shown that the lake is well mixed by wind currents and stratification occurs only in NST1 (Figure 1). This paper presents an investigation of the correlations between phosphorous concentrations, Chlorophyll-a concentrations and Secchi transparency in Lake Naivasha.

\section{Methods and Materials}

\subsection{Study Area}

Lake Naivasha is located in the eastern rift valley of Kenya $0^{\circ} 46^{\prime} \mathrm{S}$ and $36^{\circ} 20 \mathrm{E}$ at an altitude of 1890 above sea level (Mavuti et al., 1996a; Mavuti \& Harper, 2006). The lake has a catchment area of $3200 \mathrm{Km}^{2}$ and a surface area that varies between $130 \mathrm{Km}^{2}-160 \mathrm{Km}^{2}$ during the dry and wet seasons respectively. For many years, the mean depth of the lake has been between 4 metres and 6 metres and 
surrounded by a belt of papyrus (Hickley et al., 2008). Lake Naivasha is the second largest wetland of international importance (Ramsar site) designated in 1995 (Secretariat, 2013) and has two other sister smaller lakes Oloidien and Sonachi crater. The closed basin (Figure 1) with only an underground seepage (Gaudet \& Muthuri, 1981; Becht \& Harper, 2002) without any outlet has remained fresh despite pressures from catchment, the human settlement and horticultural farming. The lake's physicochemical characteristics recorded $\mathrm{pH}$ values ranging 7.5 - 8.5, Dissolved Oxygen ranges between $7 \mathrm{mg} / \mathrm{l}-9 \mathrm{mg} / \mathrm{l}$ and temperatures ranging from $20^{\circ} \mathrm{C}-25^{\circ} \mathrm{C}$. Lake Naivasha receives water from ephemeral streams where $90 \%$ comes from River Malewa draining from Nyandarua mountains with an area of $1730 \mathrm{Km}^{2}$ and River Gilgil from North with an area of $420 \mathrm{~km}^{2}$ (Harper, Oxon, \& Mavuti, 1990). The Lake is divided into four parts, three of which are partly connected; the crescent island which is the deepest (approximately $9 \mathrm{~m}$ ), the main Lake which covers an area of $150 \mathrm{~km}^{2}$ and to the east side of the Lake is Lake Oloidien which is approximately $5.5 \mathrm{~km}^{2}$. The Crater Lake (Sonachi) to the west of the main Lake is isolated from the rest and covers about $0.2 \mathrm{~km}^{2}$ (Figure 1 ).

\subsection{Study Map}

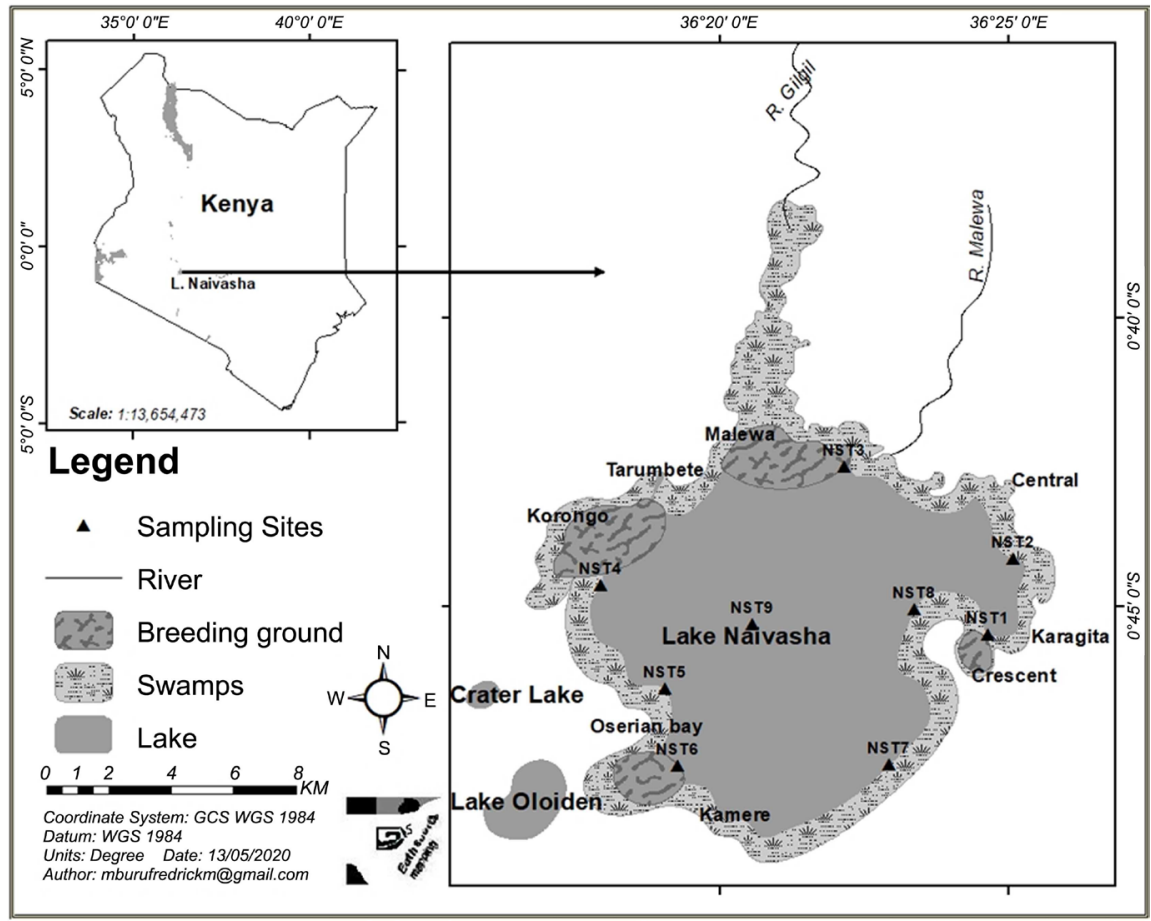

Figure 1. Location Lake Naivasha showing the 9 sampling points.

\subsection{Sampling Design}

An ecological survey design was adopted for the determination of phosphorus and chlorophyll- a concentration. Nine sampling points were selected (Figure 1) and duplicate water samples taken in at each of the stations. The water was col- 
lected from just below the surface of the lake using 1 L High Density Propylene plastic sample bottles. A portion of the water sample was immediately filtered using an acid-washed $60 \mathrm{ml}$ disposable syringe to push the water through a pre-washed GF/C glass fibre filtered (whatman). The bottles containing the filtered and unfiltered samples were transported in a cool box and analyzed in the laboratory within 1 - 3 hours from the time of collection. Water transparency was measured in situ concurrent with the water samples collections. A Secchi disc (diameter $23 \mathrm{~cm}$ ) was used to determine the transparency, according to (Bledzki, 2009) the procedure of water samples collection and transparency estimations were repeated monthly from October 2018 to October 2019. Lake levels data was recorded daily by the regional Water Resource Authority (WRA) in Naivasha.

\subsection{Sample Analysis}

Chlorophyll-a was determined by extracting a sample with $90 \%$ acetone after filtering $200 \mathrm{ml}$ volume of water sample using Whatman filter paper of $0.47 \mu \mathrm{m}$ diameter. Extraction was done by incubating the soaked sample in $15 \mathrm{ml}$ of $90 \%$ acetone. The absorbance was then recorded by a double beam spectrophotometer at $630 \mathrm{~nm}, 647 \mathrm{~nm}, 664 \mathrm{~nm}$ and $750 \mathrm{~nm}$ which was used as a blank. Total Phosphorous was determined with molybdenum blue-ascorbic method (APHA, 2005), $50 \mathrm{ml}$ duplicated samples were digested with persulphate. The colour development was advanced on the sample and the absorbance was read after 30 minutes to one hour at $880 \mathrm{~nm}$ wavelength using a double beam spectrophotometer in $1 \mathrm{~cm}$ cuvettes. A standard calibration was used to calculate the total phosphorus. Total suspended solids (TSS) were determined by filtering $200 \mathrm{ml}$ of water sample using a pre-dried and weighed filter paper of $0.47 \mu \mathrm{m}$ of diameter. The filtered sample was dried overnight at a temperature of $105^{\circ} \mathrm{C}$. The TSS levels were estimated by calculating the difference between the blank filter paper and the dried sample.

\subsection{Data Analysis}

Temporal trends in the lake levels, and phosphorus concentration were analyzed. A correlation analysis was conducted to determine the interrelationships among the lake levels, phosphorus levels, Chlorophyll- $a$ and other water quality aspects.

\section{Results}

\subsection{Lake Levels}

The study revealed lake level fluctuations in 2018 decreasing in January to march, but increased sharply from April to July and continued decreasing up to April 2019 as shown in Figure 2. The highest observed lake level was 1889 m.asl in 2013, while the lowest level was 1887.5 m.a.s.l. in February and March 2018 while the highest was 1889.5 in July 2018. 


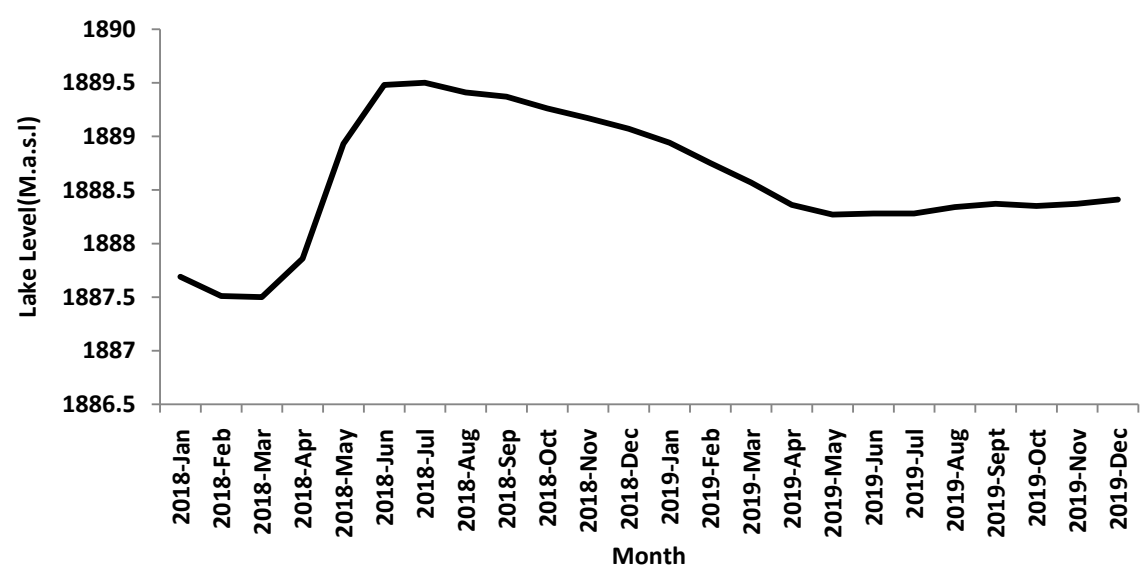

Figure 2. Shows water level changes in Lake Naivasha and monthly water levels from October 2018-2019. (Source: Water Resource Authority).

\subsection{Phosphorus Levels and Lake Levels}

From January to December 2018, results showed the highest phosphorous level in the month of June $0.42 \mathrm{mg} / \mathrm{l}$ corresponding with lake level of 1889.48 m.a.s.l. (Figure 3). The lowest phosphorus concentration $(0.20 \mathrm{mg} / \mathrm{l})$ was in the month of February corresponding with lake level of 1887.51 m.a.s.l. 2019 was slightly different 2018, the highest phosphorous concentration $0.42 \mathrm{mg} / \mathrm{l}$ in the month of February, corresponding to 1887.5 m.a.s.l. and the lowest was January $(0.33$ $\mathrm{mg} / \mathrm{l})$ at lake level of 1887.51 m.a.s.l.

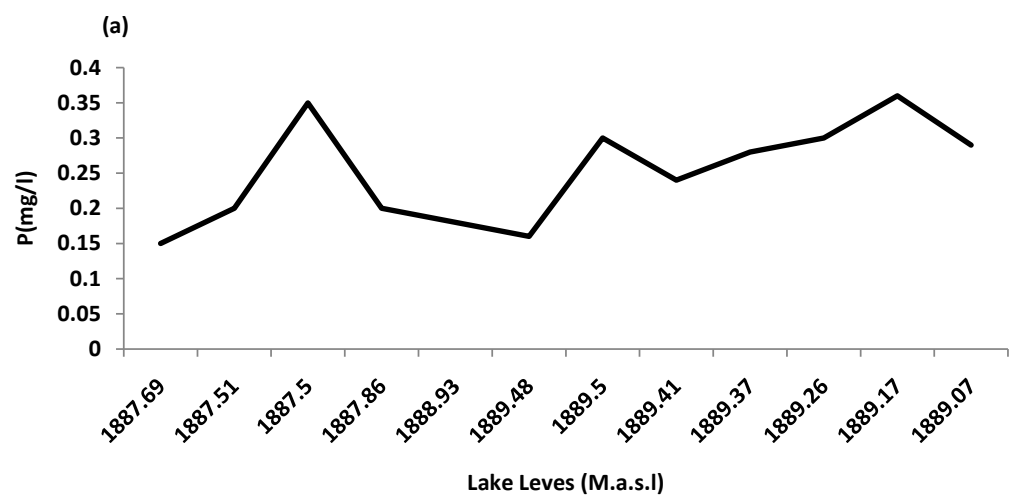

(b)

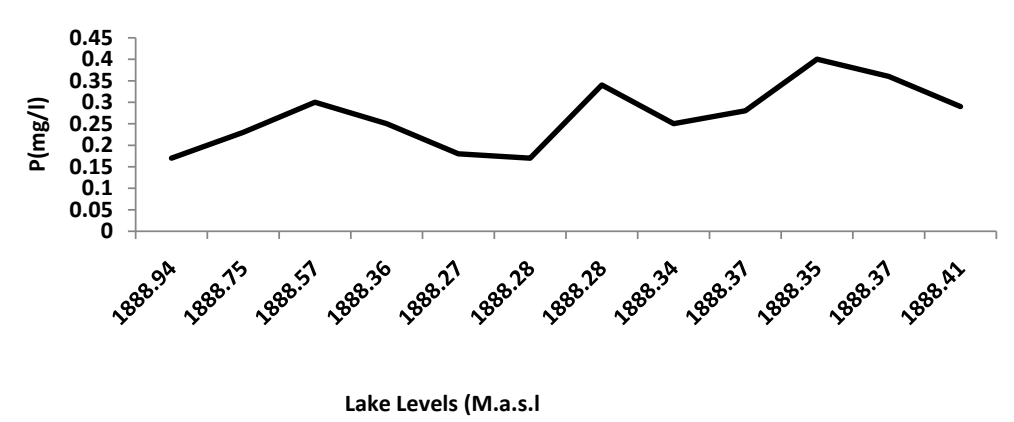

Figure 3. Lake level and phosphorus concentration relationship (a) January to December 2018 and (b) January to December 2019. 


\subsection{Mean Values of Phosphorous and Some Water Quality Aspects}

Descriptive analysis (Table 1$)$ revealed higher mean $( \pm \mathrm{SD})$ values of Chlorophyll $a$ and phosphorous in NST2 with $0.42 \pm 0.05 \mathrm{mg} \cdot \mathrm{l}^{-1}$ and $0.42 \pm 0.016 \mathrm{mg} \cdot \mathrm{l}^{-1}$ respectively, while the lowest values were in NST9 for (Chlorophyll a) with 0.32 $\pm 0.009 \mathrm{mg} \cdot \mathrm{l}^{-1}$ and NST5 for (phosphorous) with and $0.20 \pm 0.016 \mathrm{mg} \cdot \mathrm{l}^{-1}$. Mean Secchi transparency recorded the highest measurement in NST1 with $84 \pm 1.5$ $\mathrm{cm}$ and the lowest in NST3 $32.2 \pm 0.4 \mathrm{~cm}$. The highest mean TSS was recorded in NST1 with $0.144 \pm 0.004 \mathrm{~g} \cdot \mathrm{l}^{-1}$ and lowest in NST8 with $0.134 \pm 0.0028 \mathrm{~g} \cdot \mathrm{l}^{-1}$.

Table 1. Mean values of phosphorous and some water quality aspects in the two year study 2018 and 2019.

\begin{tabular}{ccccc}
\hline STN & Chlo- $(\mathrm{mg} / \mathrm{l})$ & $P(\mathrm{mg} / \mathrm{l})$ & Sech $(\mathrm{cm})$ & Tss $(\mathrm{g} / \mathrm{l})$ \\
\hline NST1 & $0.39 \pm 0.02$ & $0.24 \pm 0.007$ & $84 \pm 1.5$ & $0.144 \pm 0.004$ \\
NST2 & $0.42 \pm 0.05$ & $0.42 \pm 0.004$ & $43.7 \pm 12$ & $0.135 \pm 0.003$ \\
NST3 & $0.39 \pm 0.02$ & $0.21 \pm 0.008$ & $32.2 \pm 0.4$ & $0.14 \pm 0.003$ \\
NST4 & $0.35 \pm 0.02$ & $0.24 \pm 0.002$ & $44.5 \pm 1.87$ & $0.138 \pm 0.002$ \\
NST5 & $0.33 \pm 0.008$ & $0.20 \pm 0.016$ & $40.07 \pm 1.79$ & $0.138 \pm 0.003$ \\
NST6 & $0.32 \pm 0.005$ & $0.27 \pm 0.008$ & $34.8 \pm 0.4$ & $0.137 \pm 0.0029$ \\
NST7 & $0.33 \pm 0.007$ & $0.206 \pm 0.001$ & $34.05 \pm 1.4$ & $0.136 \pm 0.029$ \\
NST8 & $0.32 \pm 0.007$ & $0.24 \pm 0.0 .004$ & $35.4 \pm 0.4$ & $0.134 \pm 0.0028$ \\
NST9 & $0.32 \pm 0.0009$ & $0.24 \pm 0.009$ & $44.8 \pm 1.76$ & $0.140 \pm 0.003$ \\
\hline
\end{tabular}

\subsection{Relationship between Lake Levels with Chlorophyll $a$, and Phosphorous}

The results revealed a sharp increase in Chlorophyll-a with increasing water levels from the month of March until June, whereas a decrease in Chlorophyll-a with increasing water levels from July to December 2018. The phosphorous insignificantly increased in June and September, and decreased in other months. Chlorophyll-a values increased as the lake level increases while phosphorous showed insignificant increase (Figure 4(a)). In 2019 a sharp decrease was observed in chlorophyll-a with increasing water Levels from the month of January and continued to July, where there was a slight increase in chlorophyll a until the month December (Figure 4(b)). Water levels increased from January to May followed by a decline in June and July in 2018 (Figure 4(a)). The lake water levels were highest in the period October to December and lowest in the month of September 2019 (Figure 4(b)).

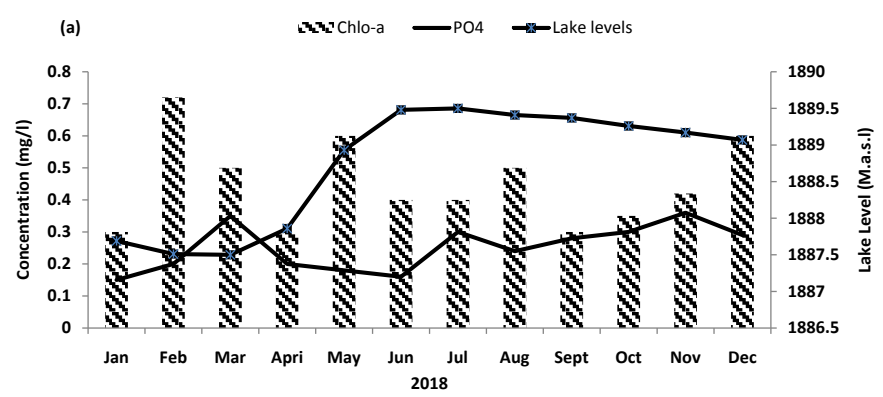




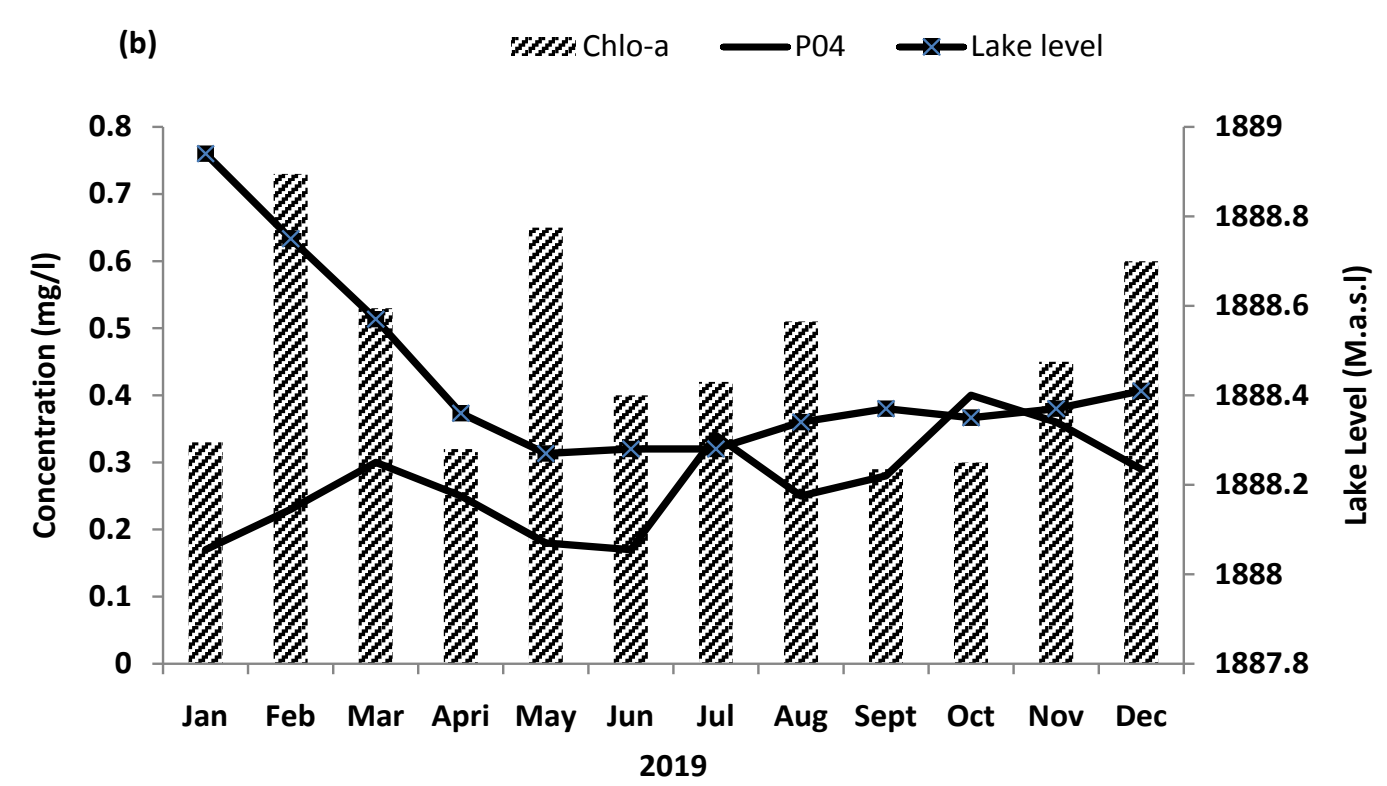

Figure 4. Relationships between the concentrations of chlorophyll a, phosphorous and water levels from January to December (a) 2018 and (b) 2019 at Lake Naivasha, Kenya.

\subsection{Chlorophyll (a) and Phosphorous Correlations with Lake Levels}

In 2018, Lake water level fluctuations had an insignificant correlation with chlorophyll (Figure $5(\mathrm{a}) ; \mathrm{R}=-0.183, \mathrm{R}^{2}=0.335 P>0.005$ and $\mathrm{N}=12$ ). The correlation was slightly better when Lake levels and phosphorous were correlated (Figure 5(b); $\left.\mathrm{R}=0.218, \mathrm{R}^{2}=0.0475\right)$. Just like in 2018, the correlation between water levels and chlorophyll-a was weak (Figure $5(\mathrm{c}) ; \mathrm{R}=0.121, \mathrm{R}^{2}=0.0206$, $P>0.05$ and $\mathrm{N}=12$ ) for the 2019. Similar observations were made when Lake levels and phosphorous were correlated (Figure $5(\mathrm{~d}) ; \mathrm{R}=0.028, \mathrm{R}^{2}=0.0008$ ).
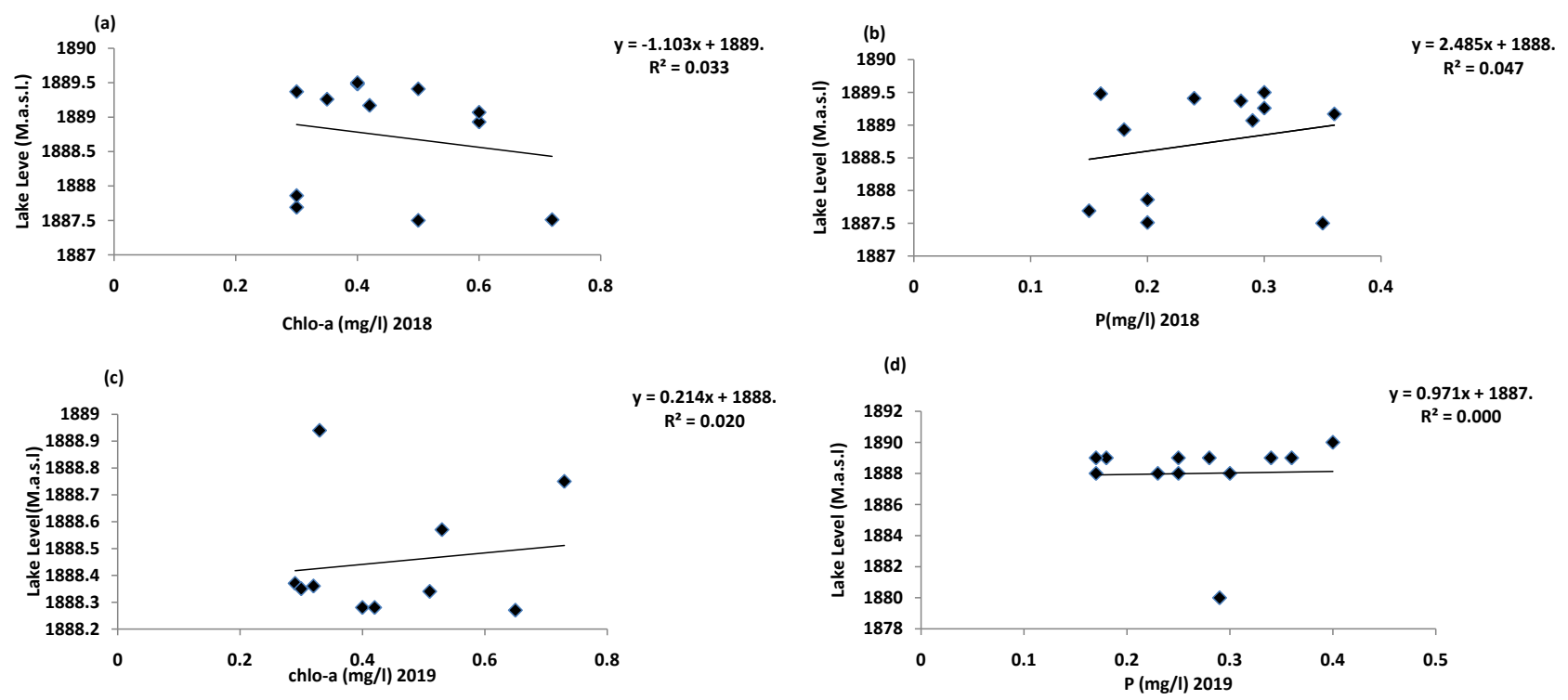

Figure 5. The correlation of lake levels with both chlorophyll $a$ and phosphorous (a \& b 2018), (correlations b \& d 2019) in Lake Naivasha; a in 2018, b in 2019. 


\subsection{Secchi Transparency Correlations with Chlorophyll- $a$ and Lake Levels}

A positive correlation was also observed between Secchi transparency and Chlorophyll a $\left(\mathrm{R}=0.334, \mathrm{R}^{2}=0.1105\right.$; Figure $\left.6(\mathrm{a})\right)$. There was slightly a positive correlation between the water levels and secchi transparency $\left(\mathrm{R}=0.102, \mathrm{R}^{2}=0.0103\right.$ $P>0.05$ and $\mathrm{N}=24$; Figure 6(b)).

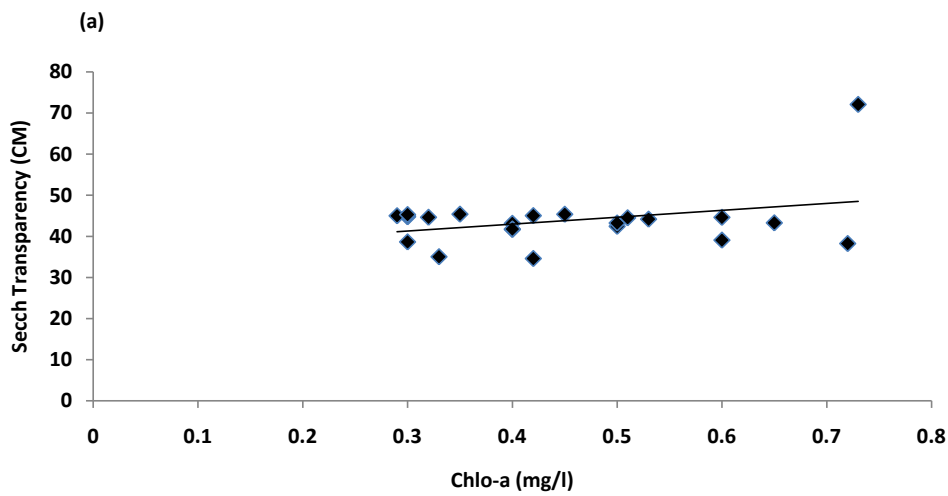

$y=16.81 x+36.23$ $R^{2}=0.110$

(b)

$y=1.139 x-2108$ $R^{2}=0.010$

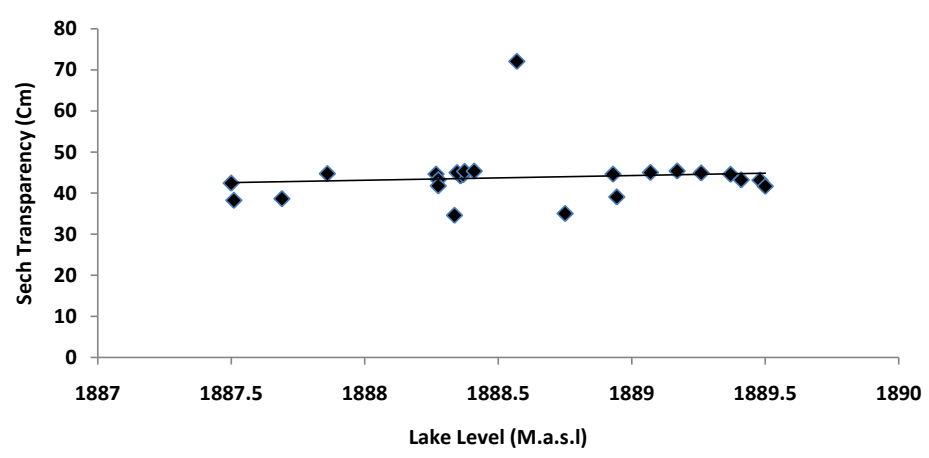

Figure 6. The correlation between secchi transparency with chlorophyll $a$ and lake levels at Lake Naivasha, Kenya.

\subsection{Secchi Transparency Correlations with Phosphorous and TSS}

A positive correlation between Secchi Transparency and Phosphorous was observed $\left(\mathrm{R}=0.264, \mathrm{R}^{2}=0.0697\right.$; Figure $7(\mathrm{a})$ ), while correlation between Secchi transparency and TSS is $\mathrm{R}=0.156 \mathrm{R}^{2}=0.0243$; Figure 7 (b).

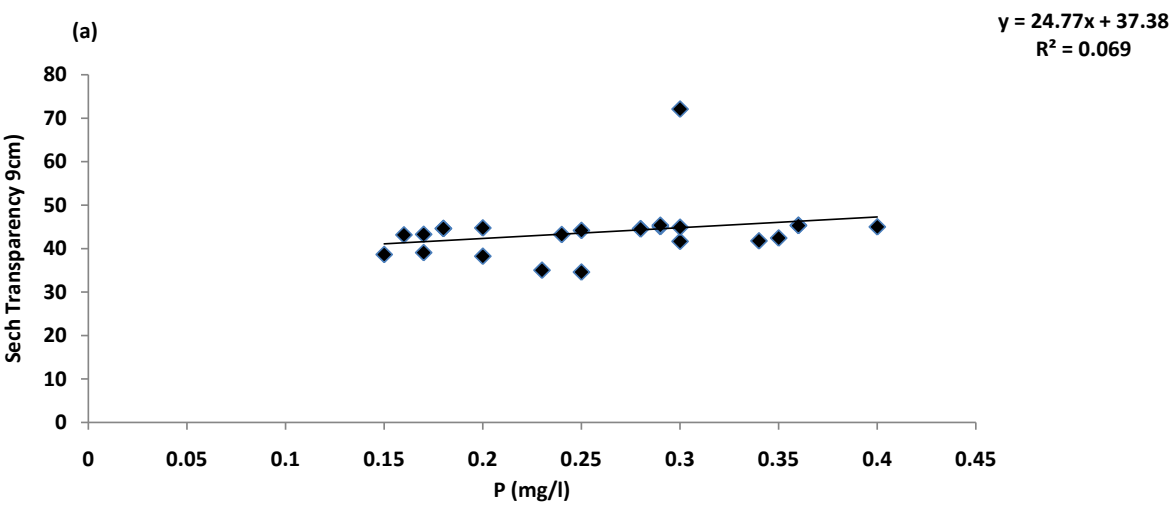




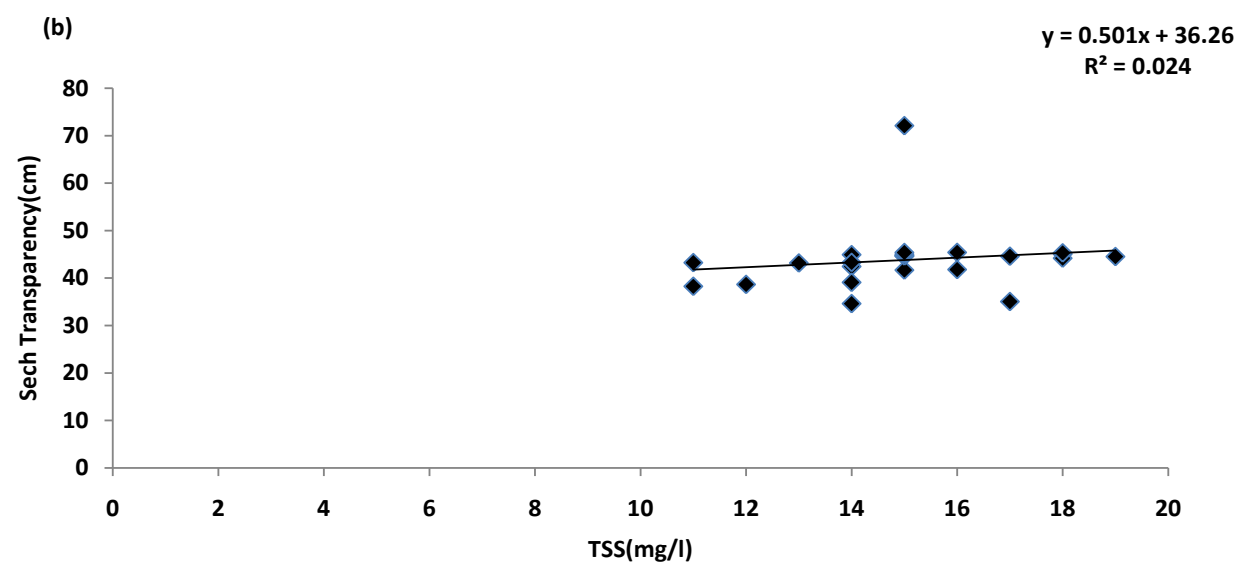

Figure 7. Correlations between TSS, phosphorous and secchi transparency at Lake Naivasha, Kenya.

\subsection{Correlations between Chlorophyll- $a$ and TSS}

A strong positive correlation was observed between Chlorophyll- $a$ and TSS ( $\mathrm{R}=$ 0.142; $\mathrm{R}^{2}=0.0202$; Figure 8) below.

TSS

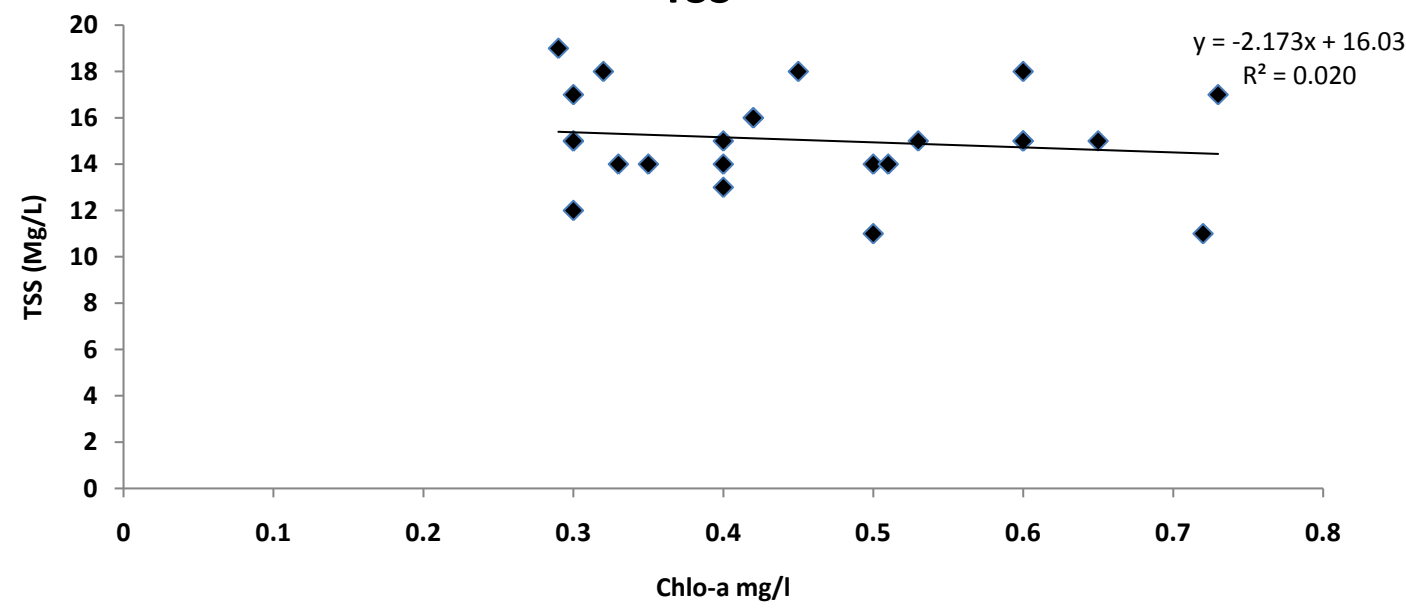

Figure 8. Correlation between chlorophyll $a$ and total dissolved solids at Lake Naivasha, Kenya.

\section{Discussion and Conclusion}

Studies show that stratified Africa Lakes have reported that $90 \%$ of incoming phosphorous is stored in sediments and thereafter released or availed for phytoplankton (chlorophyll-a) production (Zwieten et al., 2011; Lee \& Jones, 1980). Chlorophyll-a changes in most tropics shallow lakes are related to the cyclic aspects of water levels. Our findings indicated that phosphorous concentrations influence the levels of Chlorophyll-a. Increased phosphorous can be associated with availability of benthic fish (Chorus \& Bartram, 1999) which helps in re-suspension of sediments leading to mobilization rates of sediment in shallow lakes but not in deep lakes.

These findings are consistent with those from related studies that showed that changes in Chlorophyll-a concentrations are usually associated with nutrient 
supply (Benndorf \& Klaus, 1987). In Lake Naivasha, water level fluctuations have shown dramatic impacts on fish and plant communities in species variations. Studies on Lake Victoria and Lake Chilwa by (Howard-williams \& Gaudet, 1985) and by (Gaudet, 1979) on Lake Naivasha, showed that shallow lakes have risks of drying up because of rainfall patterns. These results are similar to the current study findings that demonstrated lake water levels strongly linked to the seasonal weather variations. The decrease can be associated to the reduction in phosphorous being released into the water

Our study findings on levels and variations of phosphorous at all the nine stations on the lake $(0.20 \mathrm{mg} / \mathrm{l}-0.42 \mathrm{mg} / \mathrm{l})$ are consistent with those (Kitaka et al., 2002; Ballot et al., 2009; Harper et al., 1990; Hubble \& Harper, 2002) (0.5 mg/l to $1.2 \mathrm{mg} / \mathrm{l} ; 0.07 \mathrm{mg} / \mathrm{l}-0.02 \mathrm{mg} / 10.11 \mathrm{mg} / \mathrm{l}$ to $0.178 \mathrm{mg} / \mathrm{l}$ respectively.

From the study Chlorophyll-a values ranged from $0.32 \mathrm{mg} / \mathrm{l}$ to $0.42 \mathrm{mg} / \mathrm{l}$ in all stations. To the contrary studies by Kitaka et al. (2002) showed lower values of $0.031 \mathrm{mg} / \mathrm{l}$ while Ballot et al. (2009) values were higher $14.4 \mathrm{mg} / \mathrm{l}$ to $83.9 \mathrm{mg} / \mathrm{l}$ in comparison to our study. In 2009 the lake levels were very low and hence high light penetration leading to higher photosynthetic activity.

Considerable variations in water turbidity between our study and related ones on this lake were noted, the water shows signs of eutrophication (Richardson \& Richardson, 2015; Stoof-Leichsenring et al., 2011). Our Secchi transparency values ranged from $32 \mathrm{~cm}$ to $84 \mathrm{~cm}$ which was comparable to (Harper et al., 1990) $164 \mathrm{~cm}$ to $40 \mathrm{~cm}$ in 1987 and Ballot et al. (2009) averaged $62 \mathrm{~cm}$. Results showed that TSS in all stations recorded between $0.13 \mathrm{mg} / \mathrm{l}$ to $0.14 \mathrm{mg} / \mathrm{l}$.

From the study in 2018, as the Lake levels increase, chlorophyll-a production increases. However in 2019, it is the opposite. Phosphorous displayed a common pattern or distribution in both months of 2018 and 2019.

Although nine sampling points represented the whole study area and twenty-four months of the study comparing the complexity of the lake can be a limitation, we record significant relationship between WLF and major ecosystem aspects. Phosphorous trends and other ecosystem aspects give insights of the importance of water level fluctuations as drivers of ecosystem structure and function of freshwater.

\section{Recommendations}

In recent years, Rift valley lakes have recorded increased lake levels, this is likely to cause economical and ecological risks. If the current situation of WLF continues; Lake Nakuru (1759 m.a.s.l.) is likely to connect with Lake Elementaita (1776 m.a.s.1.), while Lake Baringo (970 m.a.s.l.) is likely to connect with Lake Bogoria (990 m.a.s.l.), we recommend the government to put up tight measures to curb future loss of aquatic habitats and economies. More future studies both temporal and spatial on WLF and its relation to ecosystem aspects and other processes in tropical lakes are required both in Africa and other parts of the world. 


\section{Acknowledgements}

We thank the Government of Kenya for continued support to carry out research on our Lakes (through Kenya Marine and Fisheries Research Institute). Much appreciation to Water Resource Authority for the Data.

\section{Conflicts of Interest}

The authors declare no conflicts of interest regarding the publication of this paper.

\section{References}

APHA (2005) APHA Method 4500-P: Standard Methods for the Examination of Water and Wastewater.

Ballot, A. et al. (2009). Changes of Phytoplankton Communities in Lakes Naivasha and Oloidien, Examples of Degradation and Salinization of Lakes in the Kenyan Rift Valley. Hydrolbiologia, 632, 359-363. https://doi.org/10.1007/s10750-009-9847-0

Becht, R., \& Harper, D. M. (2002). Towards an Understanding of Human Impact upon the Hydrology of Lake towards an Understanding of Human Impact upon the Hydrology of Lake Naivasha, Kenya. Hydrobiologia, 488, 1-11. https://doi.org/10.1007/978-94-017-2031-1_1

Benndorf, J., \& Klaus, P. (1987). Control of Eutrophication of Lakes and Reseevoirs by Means of Pre-dams-i, Mode of Operation and Calculation of the Nutrient Elimination Capacity. Water Research, 21, 829-838. https://doi.org/10.1016/0043-1354(87)90159-X

Bledzki, A. L. (2009). Secchi Disk Secchi Disk Secchi Disk Description Value in Modern Limnology.

Bot, P. V. M., \& Colijn, F. (1996). A Method for Estimating Primary Production from Chlorophyll Concentrations with Results Showing Trends in the Irish Sea and the Dutch Coastal Zone. ICES Journal of Marine Science, 53, 945-950. https://doi.org/10.1006/jmsc.1996.0116

Briton, J. R. et al. (2007). From Introduction to Fishery Dominance: The Initial Impacts of the Invasive Carp Cyprinus carpio in Lake Naivasha, Kenya, 1999 to 2006. Fish Biology, 71, 239-257. https://doi.org/10.1111/j.1095-8649.2007.01669.x

Chapman, D. (1996). Water Quality Assessments-A Guide to Use of Biota, Sediments and Water in Environmental Monitoring. 2nd Edition, Great Britain: UNESCO/WHO/ UNEP.

Chorus, I., \& Bartram, J. (1999). Toxic Cyanobacteria in Water: A Guide to Their Public Health Consequences, Monitoring and Management. London and New York: F \& FN Spon 11 New Fetter Lane. https://doi.org/10.1201/9781482295061

Gaudet, J. J. (1977). Natural Drawdown on Lake Naivasha, Kenya, and the Formation of Papyrus Swamps. Aquatic Botany, 3, 1-47. https://doi.org/10.1016/0304-3770(77)90002-X

Gaudet, J. J. (1979). Seasonal Change in T in a Tropical Swamp: North Swamp Lake Naivasha, Kenya. Ecology, 67, 953-981. https://doi.org/10.2307/2259223

Gaudet, J. J. (2014). Uptake, Accumulation and Loss of Nutrients by Papyrus in Tropical Swamps. Ecology, 58, 415-422. https://doi.org/10.2307/1935616

Gaudet, J. J., \& Muthuri, F. M. (1981). Nutrient Relationships in Shallow Water in an 
African Lake, Lake Naivasha. Oecologia, 49, 109-118. https://doi.org/10.1007/BF00376907

Gikuma-Njuru, P., \& Hecky, R. E. (2005). Nutrient Concentrations in Nyanza Gulf, Lake Victoria, Kenya: Light Limits Algal Demand and Abundance. Hydrobiologia, 534, 131-140. https://doi.org/10.1007/s10750-004-1418-9

Gownaris, N. J. et al. (2018). Water Level Fluctuations and the Ecosystem Functioning of Lakes. Journal of Great Lakes Research, 44, 1154-1163. https://doi.org/10.1016/j.jglr.2018.08.005

Harper, D. M., Oxon, M. A., \& Mavuti, K. M. (1990). Ecology and Management of Lake Naivasha, Kenya, in Relation to Climatic Change, Alien Species' Introductions, and Agricultural Development. Environmental Conservation, 17, 328-336. https://doi.org/10.1017/S037689290003277X

Hecky, R. E., \& Kling, I. J. (1981). The Phytoplankton and Protozooplankton of the Euphotic Zone of Lake Tanganyika: Species Composition, Biomass, Chlorophyll Content, and Spatio-Temporal Distribution. Limnology and Oceanography, 26, 548-564. https://doi.org/10.4319/lo.1981.26.3.0548

Hickley, P. et al. (2002). The Status and Future of the Lake Naivasha Fishery, Kenya. Hydrobiologia, 488, 181-190. https://doi.org/10.1023/A:1023334715893

Hickley, P. et al. (2008). Economic Gain versus Ecological Damage from the Introduction of Non-Native Freshwater Fish: Case Studies from Kenya. The Open Fish Science Journal, 1, 36-46. https://doi.org/10.2174/1874401X00801010036

Howard-williams, C. and Gaudet, J. J. (1985). The Structure and Functioning of African swamps. In: Denny, P. (Eds) The Ecology and Management of African Wetland Vegetation. Dordrecht: Springer.

Howard-Williams, C., \& Lenton, G. M. (1975). The Role of the Littoral Zone in the Functioning of a Shallow Tropical Lake Ecosystem. Freshwater Biology, 5, 445-459. https://doi.org/10.1111/j.1365-2427.1975.tb00147.x

Hubble, D. S., \& Harper, D. M. (2002). Nutrient Control of Phytoplankton Production in Lake Naivasha, Kenya. Hydrobiologia, 488, 99-105. https://doi.org/10.1023/A:1023318212258

Jones, R. A., \& Lee, G. F. (1982). Recent Advances in Assessing Impact of Phosphorus Load on Eutrophication-Related Water Quality. Water Research, 16, 503-515. https://doi.org/10.1016/0043-1354(82)90069-0

Junk, W. J., Bayley, P. B., \& Sparks, R. E. (1989). The Flood Pulse Concept in River-Floodplain Systems. Canadian Journal of Fisheries and Aquatic Sciences, 106, 110-127.

Kalff, J. (1983). Phosphorus Limitation in Some Tropical African Lakes (pp. 1-12). Leicester: University of Leicester. https://doi.org/10.1007/BF00027425

Kalff, J., \& Brumelis, D. (1993). Nutrient Loading, Wind Speed and Phytoplankton Biomass in a Tropical African Lake. Internationale Vereinigung für theoretische und angewandte Limnologie: Verhandlungen, 25, 860. https://doi.org/10.1080/03680770.1992.11900267

Kalffi, J. (1986). Phytoplankton and Its Dynamics in Two Tropical Lakes: A Tropical and Temperate Zone Comparison. Hydrolobiologia, 138, 161-176. https://doi.org/10.1007/BF00027238

Kilham, P. (1990). Endless Summer: Internal Loading Processes Dominate Nutrient Cycling in Tropical Lakes. Freshwater Biology, 23, 379-389. https://doi.org/10.1111/j.1365-2427.1990.tb00280.x

Kitaka, N., Harper, D. M., \& Mavuti, K. M. (2002). Phosphorus Inputs to Lake Naivasha, 
Kenya, from Its Catchment and the Trophic State of the Lake. Hydrobiologia, 488, 73-80. https://doi.org/10.1023/A:1023362027279

Kolding, J. et al. (2016). Fisheries in the Drylands of Sub-Saharan Africa "Fish Come with the Rains"(pp. 1-64). Fisheries and Aquaculture.

Kolding, J., \& Zwieten, P. A. M. Van (2012). Relative Lake Level Fluctuations and Their Influence on Productivity and Resilience in Tropical Lakes and Reservoirs. Fisheries Research, 115-116, 99-109. https://doi.org/10.1016/j.fishres.2011.11.008

Krienitz, L. et al. (2013). The Rise of Potentially Toxin Producing Cyanobacteria in Lake Naivasha, Great African Rift Valley, Kenya. Harmful Algae, 27, 42-51. https://doi.org/10.1016/j.hal.2013.04.005

Lee, F. G., \& Jones, R. (1980). Availability of Phosphorous to Phytoplankton and Its Implications for Phosphorous Management Strategies (pp. 1-42). Washington DC: International Joint Commission.

Mavuti, K. M., \& Harper, D. M. (2006). The Ecological State of Lake Naivasha, Kenya, 2005: Turning 25 Years Research into an Effective Ramsar Monitoring Programme.

Mavuti, K., Moreau, J., \& Munyandorero, J. (1996a). Analysis of Trophic Relationships in Two Shallow Equatorial Lakes Lake Naivasha (Kenya) and Lake Ihema (Rwanda) Using a Multispecifies Trophic Model. Hydrobiologia, 321, 89-100. https://doi.org/10.1007/BF00023166

Mclachlan, S. M. (1971). The Rate of Nutrient Release from Grass and Dung Following Immersion in Lake Water. Hydrolobiologia, 37, 521-530. https://doi.org/10.1007/BF00018817

Melack, J. M. (1979). Photosynthetic Rates in Four Tropical African Fresh Waters. Freshwater Biology, 9, 555-571. https://doi.org/10.1111/j.1365-2427.1979.tb01539.x

Moed, R., \& Hallegraeff, M. G. (1978). Some Problems in the Estimation of Chlorophyll-a and Some Problems in the Estimation of Chlorophyll-a and Phaeopigments from Preand Post-Acidification. Hydrolbiol, 6, 787-800.

https://doi.org/10.1002/iroh.19780630610

Odongo, V. O. et al. (2015). Characterisation of Hydroclimatological Trends and Variability in the Lake Naivasha Basin, Kenya. Hydrological Processes, 29, 3276-3293. https://doi.org/10.1002/hyp.10443

Pacini, N. et al. (2018). Papyrus as an Ecohydrological Tool for Restoring Ecosystem Services in Afrotropical Wetlands. Ecohydrology \& Hydrobiology, 18, 142-154. https://doi.org/10.1016/j.ecohyd.2018.02.001

Richardson, J. L., \& Richardson, A. E. (2015). Ecological Society of America History of an African Rift Lake and Its Climatic Implications. Ecological Monographs, 42, 499-534. https://doi.org/10.2307/1942169

Richardson, K. (1985). Plankton Distribution and Activity in the North Sea/SkagerrakKattegat Frontal Area in April 1984. Marine Ecology Progress Series, 26, 233-244. https://doi.org/10.3354/meps026233

Richardson, K., \& Heilmann, P. J. (1995). Primary Production in the Kattegat: Past and Present. Ophelia, 1, 317-328. https://doi.org/10.1080/00785236.1995.10422050

Roach, K. A., \& Winemiller, K. O. (2014). Effects of Flow, Turbidity and Nutrients Autochthonous Production in Shallow Littoral Zones of Five Floodplain Rivers: Effects of Flow, Turbidity and Nutrients. Freshwater Biology, 59, 1278-1293. https://doi.org/10.1111/fwb.12347

Secretariat, R. C. (2013). The Ramsar Convention Manual: A Guide to the Convention on Wetlands (Ramsar, Iran, 1971) (6th ed.). Gland: Ramsar Convention Secretariat. 
Stoof-Leichsenring, K. R. (2011). Environmental Variability in Lake Naivasha, Kenya, over the Last Two Centuries. Journal of Paleolimnology, 45, 353-367.

https://doi.org/10.1007/s10933-011-9502-4

Stoof-Leichsenring, K. R. et al. (2011). Environmental Variability in Lake Naivasha, Kenya, over the Last Two Centuries. Journal of Paleolimnology, 45, 353-367. https://doi.org/10.1007/s10933-011-9502-4

Stoof-Leichsenring, K. R., Epp, L. S., \& Trauth, M. H. (2012). Hidden Diversity in Diatoms of Kenyan Lake Naivasha: A Genetic Approach Detects Temporal Variation. Molecular Ecology, 21, 1918-1930. https://doi.org/10.1111/j.1365-294X.2011.05412.x

Talling, F. (1992). Environmental Regulation in African Shallow Lakes and Wetlands. Hydriobiolgia, 25, 87-144.

Talling, J. F. (2001). Environmental Controls on the Functioning of Shallow Tropical Lakes. Hydrobiologia, 458, 1-8.

Zwieten, V. et al. (2011). Review of Tropical Reservoirs and Their Fisheries-The Cases of Lake Nasser, Lake Volta and Indo-Gangetic Basin Reservoirs. Fisheries and Aquaculture, 1-148. 